\title{
Development and Evaluation of a Novel Drug Delivery System for Albendazole
}

\author{
Shaikh Karimunnisa ${ }^{1 *}$, Pandhe Puja², Kale Sangita1, Bothiraja Chellampillai² \\ ${ }^{1}$ Department of Quality Assurance Techniques, Progressive Education Society's Modern College of Pharmacy, Yamunanagar, Nigdi, \\ Pune, Maharashtra, INDIA. \\ 2Department of Pharmaceutics, Poona College of Pharmacy, Paud Road, Erandawane, Pune, Maharashtra, INDIA.
}

\begin{abstract}
Introduction: The main objective of the present study was to develop and evaluate long circulating pegylated niosomal formulation of albendazole (ABZ). It was hypothesized thatpegylated niosomes would increase the systemic residence time of albendazole in the treatment of echinococcosis thus obviating frequent doses of albendazole. Materials and methods: $A B Z$ was received as a gift sample from SeQuent Scientific Limited, Mahad. Span 60 niosomes pegylated with Distearoyl-sn-glycero-3-phosphoethanolamine (DSPE-PEG procured from Sigma Aldrich) were prepared by ethanol injection method. They were evaluated for particle size, entrapment efficiency, zeta potential, in-vitro release and pharmacokinetic study. Results and discussion: The pegylated niosomes were $296.39 \pm 0.62 \mathrm{~nm}$ in size and spherical in nature. The nanosize of the niosomes will probably help in targeting the site of treatment of echinococcosis. Zeta potential, encapsulation efficiency and in-vitro release were $3.44 \mathrm{mV}, 98.97 \% \mathrm{w} / \mathrm{v}$ and $92.93 \%$ $\mathrm{w} / \mathrm{v}$ respectively. T90 of pegylated niosomes was found to be twice (1440.8 min) as that of free dug (720.2 $\mathrm{min})$. Thus pegylated niosomes prolonged the release of albendazole. Hemolysis produced was less than $3 \%$; thus niosomes proved safe for intravenous injection. Conclusion: Developed pegylated niosomes have potential in the treatment of echinococcosis and hydatid cysts. These niosomes will probably reduce the frequency of administration of albendazole.
\end{abstract}

Key words: Niosomes, Prolonged release, PEG-DSPE, Pegylation, Albendazole.

\section{INTRODUCTION}

Alveolar echinococcosis (AE) is a potentially fatal, chronically progressive parasitic infection characterized by a long asymptomatic period and development of an invasive tumor-like lesion throughout this period. Early diagnosis of AE is very difficult because of long latent or asymptomatic period which may be as long as 20 years. The clinical diagnosis is based on patient history including epidemiological data, clinical findings, morphological lesions detected by imaging studies such as ultrasonography (US), computerized tomography (CT), magnetic resonance imaging (MRI), and immunodiagnostic tests such as the enzyme-linked immunosorbent assay, using purified echinococcus multilocularis antigen (Em2-ELISA) as a serodiagnostic marker. ${ }^{1}$ Humans act as intermediate hosts for Echinococcus species and are infected when they ingest tapeworm eggs from the definitive host. The eggs may be eaten in foods such as vegetables, fruits or herbs, or drunk in contaminated water. They can also stick to the hands when a person pets an infected dog or cat, handles a wild animal or its carcass, or touches contaminated soil and vegetation. ${ }^{2}$ Cysts formed in human body are often removed surgically. The success rate varies with the species of echinococcus and the location and size of the cyst(s). ${ }^{3}$

Albendazole (ABZ), methyl [5-(propyl thio)-1-H-benzimidazol-2yl] carbamate, is a benzimidazole derivative effective in the
Submission Date: 09-10-2017; Revision Date: 05-12-2017; Accepted Date: 06-12-2017

DOI: 10.5530/ijper.52.3.47 Correspondence: Shaikh Karimunnisa, Department of Quality Assurance Techniques, Progressive Education Society's Modern College of Pharmacy, Yamunanagar, Nigdi, Pune 411044, Maharashtra, INDIA. Phone: 9881865610 E-mail: karima78@rediffmail. com

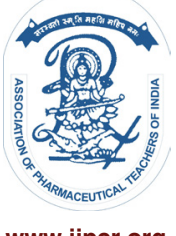

www.ijper.org 
treatment of echinococcosis, hydatid cysts and neurocysticercosis. ${ }^{4,5}$ It demonstrates variable, unpredictable and low therapeutic response $(20 \%$ to $50 \%)$ in cases of echinococcosis. ${ }^{6}$ The probable reason is ABZ's poor intestinal absorption (5\%) due to its low aqueous solubility. ${ }^{7}$ This orally administered BCS Class II broad-spectrum anthelmintic is given in higher doses 2-3 times a day for 6 months to year for hydatid disease. ${ }^{8,9}$ Headache, bleeding and vomiting are few side effects observed. Repeated dose therapy is the only treatment for this disease and a course of ABZ for prescribed period has to be completed by the patients. Hence there is a need to minimize the dose and dosing frequency which will lead to lesser side effects and thus increase the efficacy of ABZ. ${ }^{10}$ Previous reports indicated chemo prophylactic and clinical efficacy of albendazole formulated as solid dispersions in experimental cystic echinococcosis which impairs the development of the hydatid cysts. ${ }^{11}$ Albendazole-chitosan microspheres have been reported by some author for alveolar echinococcosis in mice. ${ }^{12}$ Albendazole sulfoxide is also used in patients with hydatid disease. ${ }^{13}$ There is evidence from sources for the efficacy and safety of albendazole (ABZ) obtained in the last few years. ${ }^{14}$

Thus, very few reports of enhancement of therapeutic efficacy of ABZ in echinococcosis are available. There is a need for development of other drug delivery modalities. Niosomes are vesicular constructs of non-ionic surfactants that are widely used in drug delivery technology. These non-ionic surfactant vesicles are capable of entrapping hydrophilic and hydrophobic molecules. ${ }^{15}$ They are uni or multi lamellar vesicles and are formed from synthetic, non ionic surfactant of alkyl or di-alkyl poly glycerol ether class. They offer several advantages desired by formulation scientists. They improve the therapeutic performance of the drug by protecting it from the biological environment and restricting effects to target cells, thereby reducing the clearance of the drug. They act as a depot to release the drug slowly and offer a controlled release. They can increase the oral bioavailability of drugs, increase the stability of the entrapped drug and enhance the skin penetration of drugs. Moreover, the surfactants used are biodegradable, biocompatible, and non immunogenic; thus niosomes can be made to reach the site of action by oral, parenteral as well as topical route. ${ }^{16}$ Rokade V.S. reported that ciprofloxacin in niosomal cream demonstrated improved skin retention and prolonged local effect for complete eradication of bacterial infection. ${ }^{17}$ The PEG-DSPE block copolymers have been employed to prepare PEGylated liposomes, which are biocompatible, inert and could be characterized by a long half-life in the plasma compartment in vivo. ${ }^{18,19}$ Kumar et.al. concluded that pregabalin encapsulated in niosomes showed prolonged release and longer duration of action thereby achieving sustained release. ${ }^{20}$ Gyati et al. revealed that niosomal formulations of clarithromycin provided sustained and prolonged delivery of drug with enhanced bioavailability. ${ }^{21}$ PEGylation is the process of both covalent and non-covalent attachment or amalgamation of polyethylene glycol (PEG) polymer chains to molecules and macrostructures such as a drug, therapeutic protein or vesicle, which is then described as PEGylated. It is routinely achieved by incubation of a reactive derivative of PEG with the target molecule. The covalent attachment of PEG is known to "mask" the attached drug or protein from the host's immune system leading to reduced immunogenicity and antigenicity. It is also known to increase the hydrodynamic size of the agent which prolongs its circulatory time by reducing renal clearance. It can also provide water solubility to hydrophobic drugs and proteins. PEGylation offers new prospects for designing new drug delivery modules and dosing regimens. ${ }^{22,23}$ In a study reported by Zarei et al. pegylated niosomes proved better than pegylated liposomes for delivery of paclitaxel. ${ }^{24} \mathrm{~A}$ report by He et al. suggested that pegylated niosomes served efficient carrier for paenol that effectively solubilized, stabilized and delivered the drug to the cancer cells. ${ }^{25}$ Another report by Huang $\mathrm{Y}$ et.al concluded that pegylated niosomes improved the stability and cellular delivery of oligosaccharides. ${ }^{26}$ Azizi and Norouzian too demonstrated enhanced activity of niosomes of letrozole a potent agent in breast cancer treatment. ${ }^{27}$ Arora et.al reviewed pharmaceutical applications of nano-niosomes in drug, vaccine and gene delivery. Pegylated hydroxyl camptothecin niosome resulted in stealth effect which showed high antitumor activity of camptothecin. ${ }^{28}$

The aim of the present study was to increase the efficacy of $\mathrm{ABZ}$ by formulating a long circulating vesicular system. The niosomal encapsulation shall control drug release and PEGylation would further prolong in-vivo release of ABZ. Thus, pegylated niosomes containing ABZ were prepared and evaluated for size, entrapment efficiency, in vitro drug release, hemolytic activity and invivo pharmacokinetic profiling.

\section{MATERIALS AND METHODS}

\section{MATERIALS}

ABZ was obtained as a gift sample from Sequent Scientific Limited, M.I.D.C. Mahad. DSPE PEG-5000 was received from Sigma Aldrich. Cholesterol and Span 
60 were received from LOBA Chemie, Thane. All other chemicals and solvents used for the analytical determination of $\mathrm{ABZ}$ were of analytical grade.

\section{METHODS}

Preparation of Niosomes: Niosomes were prepared by modified ethanol injection method. ${ }^{29}$ ABZ (50mg), span $60(100 \mathrm{mg})$ and cholesterol $(150 \mathrm{mg})$ were dissolved in $10 \mathrm{ml}$ of ethanol. The resulting solution was slowly injected using micro syringe at a rate of $0.25 \mathrm{ml} / \mathrm{min}$ into $10 \mathrm{ml}$ of water. The solution was stirred continuously on magnetic stirrer and temperature was maintained above $60^{\circ} \mathrm{C}$. As the lipid solution was injected slowly into aqueous phase, stirring continued for 1-1.5 hrs. Vaporization of solvent takes place, resulting in spontaneous vesiculation and formation of unilamellar spherical niosomes. After formation of niosomes, DSPE PEG5000 (3mg) was added to the niosomal dispersion and stirred continually for $1 \mathrm{~h}$ at $25^{\circ} \mathrm{C}$ to obtain PEGylated niosomes. This dispersion was bath sonicated for $25 \mathrm{~min}$ to reduce particle size of any aggregates formed and stored at $2-8^{\circ} \mathrm{C}$ until further use.

\section{Vesicle size and shape analysis}

The average particle size of pegylated niosomes were measured by the method of laser light diffraction using NANOPHOX (NX0088) particle analyzer. Prior to measurements, samples were dispersed with $100 \mathrm{ml}$ of water. The particle size distributions were estimated by setting the intensity of the scattered light at wavelength of $750 \mathrm{~nm}$ and the scattering angle $(\theta)$ of $90^{\circ} \mathrm{C} .30,31$

\section{Entrapment efficiency (EE)}

The prepared ABZ loaded non-pegylated and pegylated niosomes were separated from un-entrapped drug by centrifugation at $3000 \mathrm{rpm}$ for $30 \mathrm{~min}$. The supernatant was suitably diluted to measure free drug concentration. The pellet was dispersed in ethanol to break the vesicles and appropriate dilutions were made to measure encapsulated drug concentration. ABZ concentrations were estimated by UV spectroscopy at $297 \mathrm{~nm} .{ }^{32}$ The $\%$ entrapment efficiency was calculated using the following formula:

$$
\% \mathrm{E} . \mathrm{E}=\frac{\text { Entrapped drug }}{\text { Entrapped drug }+ \text { Drug in supernatant }} \times 100
$$

\section{Zeta potential}

Zeta potential of non-pegylated and pegylated niosomes was measured using Zeta sizer Nano ZS. The niosomal samples were diluted and measurements were carried out at $25^{\circ} \mathrm{C}^{33}$

\section{Differential Scanning Calorimetry}

DSC measurements were performed on a differential scanning calorimeter equipped with an intra-cooler (DSC Mettler STAR SW 9.20, Switzerland). Inert atmosphere was maintained by purging nitrogen gas at a flow rate of $50 \mathrm{ml} / \mathrm{min}$. All accurately weighed samples (about 3-5 mg) were placed in a sealed aluminum pan, and the samples were heated under nitrogen gas flow $(20 \mathrm{ml} / \mathrm{min})$ at a scanning rate of $10^{\circ} \mathrm{C}$ per min from 40 to $240^{\circ} \mathrm{C}$. An empty aluminum pan was used as reference.

\section{Powder X-ray diffraction study}

X-Ray diffraction studies provide information about the crystallinity of the sample, which is reflected by a characteristic fingerprint region in the diffraction pattern. Studies were carried out using Philips Expertpro MPD diffractometer (PAN analytical Inc, Germany) with resolution of $0.001 \mathrm{~A}^{\circ}$. Vacuum grease was applied over the glass slide to stick the sample. About $10 \mathrm{mg}$ of sample was sprinkled over to make a layer having a thickness of $\sim 0.5 \mathrm{~mm}$. The samples were radiated using a Cu target tube and exposed to all lines $(\lambda-1.54056)$. Scanning angles $2 \theta$ ranged from $5^{\circ}$ to $40^{\circ}$ of. The current used was $30 \mathrm{~mA}$ and voltage of $40 \mathrm{kV}$.

\section{In vitro release study}

In vitro release of albendazole from niosomes was studied by dialysis method using a dialysis sac $(12,000 \mathrm{MW}$ cut off; Sigma-Aldrich) filled with test samples suspended in $150 \mathrm{~mL}$ of phosphate-buffer $(\mathrm{pH} 7.4)$ at $37^{\circ} \mathrm{C}$ at $50 \mathrm{rpm}$. Three different sacs were prepared containing free albendazole as control, albendazole in conventional niosomes and albendazole in PEGylated niosomes (each containing equivalent amount of ABZ). The two ends of the dialysis sac were tightly bound with threads. The sac was hung inside a conical flask with the help of a glass rod so that the portion of the dialysis sac with the formulation dipped into the buffer solution. The beaker was kept under stirring maintained at $100 \mathrm{rpm}$ at $37^{\circ} \mathrm{C}$ with a thermostatic control. Samples were collected at $15 \mathrm{~min}, 30 \mathrm{~min}, 45 \mathrm{~min}, 1 \mathrm{hrs}, 2 \mathrm{hrs}, 3 \mathrm{~h}$ and further $1 \mathrm{~h}$ interval over a period of $24 \mathrm{~h}$ and assayed spectrophotometrically for ABZ content at $297 \mathrm{~nm}$. Equal volume of fresh release medium was replaced at the same time intervals. The dissolution data was analyzed for percentage cumulative drug released at different time intervals.

\section{Kinetics of drug release}

The kinetics of the drug release was evaluated by model fitting method using PCP Disso v3 software and the model with the highest correlation coefficient amongst 
them was considered to be the best model for kinetics of drug release.

\section{Hemolytic assay}

Fresh rat blood $(10 \mathrm{ml})$ was collected from healthy donors; fibrogen was removed using ethanol and subsequently the blood was diluted with aqueous $\mathrm{NaCl}$ solution $(0.9 \% \mathrm{w} / \mathrm{v})$ and centrifuged at $2000 \mathrm{rpm}$ for $15 \mathrm{~min}$. The supernatant was removed and the precipitate was washed with normal saline. The washed precipitate was diluted with aqueous $\mathrm{NaCl}$ solution $(1: 50 \mathrm{v} / \mathrm{v})$ to obtain a $2 \%$ red blood cell suspension. Tubes were labeled from 1-7 and each number represented a set of three tubes. To all of the tubes, $2.5 \mathrm{ml}$ of red blood cell suspension was added. The tubes labeled 1 were diluted with $2.5 \mathrm{ml}$ of distilled water as the hemolysis control (100\% hemolysis) and the tubes labeled 2 were diluted with $2.5 \mathrm{ml}$ of $0.9 \%$ isotonic $\mathrm{NaCl}$ solution as the non-hemolysis control ( $0 \%$ hemolysis). The remaining tubes were diluted with $\mathrm{ABZ}$ niosomal suspensions corresponding to $\mathrm{ABZ}$ concentration of $0.25,0.5,0.75$, 1 and $1.5 \mathrm{mg} / \mathrm{ml}$ of niosomal suspension and volume made up to $5 \mathrm{ml}$ with $0.9 \%$ isotonic $\mathrm{NaCl}$ solution. All tubes were incubated for $1 \mathrm{~h}$ at $37^{\circ} \mathrm{C}$ and then for $5 \mathrm{~min}$ at $0^{\circ} \mathrm{C}$ to stop hemolysis. Tubes were dislodged and centrifuged at $2000 \mathrm{rpm}$ for $15 \mathrm{~min}$. Absorbance of supernatant was determined at $453 \mathrm{~nm}$ with UV-VIS spectrometer. The hemolytic rate (HR) was calculated according to the equation:

$$
\% \text { Hemolytic rate }=\frac{\mathrm{Abs}-\mathrm{Abs}_{0}}{\mathrm{Abs}_{100}-\mathrm{Abs}_{0}} \times 100
$$

Where Abs, $\mathrm{Abs}_{100}$ and $\mathrm{Abs}_{0}$ were the absorbance of the sample, and absorbance of the sample in solution of $100 \%$ and $0 \%$ hemolysis, respectively. ${ }^{34}$

\section{Pharmacokinetic study in rats}

Male Wistar albino rats weighing 150-200 g were used for the study. The animals were housed in polypropylene cages and maintained under environmental condition of temperature $25 \pm 1^{\circ} \mathrm{C}$ and relative humidity of $45-55 \%$ under $12 \mathrm{~h}$ light : $12 \mathrm{~h}$ dark cycle. The animals had free access to food pellet and water ad libitum. All the experimental protocols were approved by the Institutional Animal Ethics Committee (IAEC) of Modern College of Pharmacy, Nigdi, Pune constituted under the guidelines of Committee for the Purpose of Control and Supervision of Experiment on Animals (CPCSEA, India) with protocol approval number MCP/IAEC/184/2015. The CPCSEA guidelines were adhered to during the housing and experimentation of the animals.

\section{Experimental design and sample collection}

The rats were randomly divided into three groups (three animals each). Animals were fasted, but provided free access to water, overnight before the commencement of the experiment. Group I received ABZ suspension at the dose of $20 \mathrm{mg} / \mathrm{kg}$ by intravenous route (i.v) route. Group II and III received non-pegylated ABZ niosomes and pegylated $\mathrm{ABZ}$ niosomes respectively at the dose of equivalent to $20 \mathrm{mg} / \mathrm{kg}$ ABZ by i.v. After mild ether anaesthesia, blood samples were collected using retro-orbital puncture technique at predetermined time intervals $(0.25,0.5,1,3,6,8,12,16,20$ and $24 \mathrm{~h})$ in heparinized tubes serially ( 0.5 to $2 \mathrm{ml}$ each). Samples were centrifuged at $5000 \mathrm{rpm}$ for $35 \mathrm{~min}$ at $4^{\circ} \mathrm{C}$ and the plasma obtained was stored in polypropylene tubes below $-20^{\circ} \mathrm{C}$ and promptly analyzed by HPLC method..$^{35}$

\section{Analytical method}

The amount of albendazole was determined by the reverse-phase HPLC method. The HPLC (Water 600) apparatus consisted of quaternary (gradient system), HPLC pump (isocratic) equipped with $30 \mathrm{w}$ high resolution UV/Vis detector DATA ACE Chromatography Software (version 1.50) integrator software and a Grace smart RP C18 column $(4.6 \mathrm{~mm} \times 250 \mathrm{~mm}$ and $10 \mathrm{~mm}$ particle size). The mobile phase consisted of a mixture of acetonitrile: water $(60: 40 \mathrm{v} / \mathrm{v})$ at a flow rate of $1 \mathrm{ml} / \mathrm{min}$ that led to retention time of $7 \mathrm{~min}$ when detection was carried out at $235 \mathrm{~nm}$. The method was validated in terms of accuracy $(\% \mathrm{CV}=1.31)$ and precision $(\% \mathrm{CV}=1.19) .{ }^{36}$

\section{Pharmacokinetic and statistical analysis}

The pharmacokinetic parameters were analysed by a non-compartmentalised model with the aid of the Kinetica software version 5.0. Peak plasma concentration (Cmax) and times to reach peak concentration (Tmax) were determined from the individual plasma concentration-time curves. The terminal elimination half-life $\left(t_{1 / 2}\right)$ was calculated as $0.693 / \mathrm{Ke}$. The area under the plasma concentration-time curve (AUC) was calculated using the log-linear trapezoidal rule. Mean residence time (MRT) was calculated as AUMC/AUC. The differences in pharmacokinetic parameters of the study groups were statistically evaluated by the t-test.

Statistical analysis: Data are reported as mean \pm SD, unless otherwise stated. Statistical analysis was carried out using Graph Pad Prism 7.00 software. All statistical data was analyzed with the one way analysis of variance 
(ANOVA) test and Kruskal-Wallis test. Difference was considered to be significant at a level of $p<0.05$.

\section{RESULTS AND DISCUSSIONS}

Several strategies are being explored to improve treatment efficacy of the neglected disease, alveolar echinococcosis. These include identification of novel chemotherapeutically valuable compounds or repurposing available broad-spectrum anti-parasitic or anti-cancer drugs and compound classes that are already marketed, or that are in development for other applications. The availability of comprehensive Echinococcosis genome information and gene expression data and in vitro and in vivo models that give more detailed information on the host-parasite interactions that occur during drug treatments has really boosted the discovery of new molecules. ${ }^{37}$

Another strategy which focuses on improving the treatment efficacy of alveolar echinococcosis is designing a suitable drug delivery system. The present study addresses this strategy and aims at developing pegylated niosomes as better alternative to oral albendazole delivery. Pegylated niosomes containing albendazole were prepared by modified ethanol injection method and evaluated for various parameters.

\section{In-vitro characterization}

As seen in Figure 1(a) and 1(b), the average particle size of non-pegylated and pegylated ABZ niosomes was found to be $111.11 \mathrm{~nm} \pm 0.56$ and $296.39 \mathrm{~nm} \pm 0.62$ with polydispersity index of $0.0974 \pm 0.32$ and $0.2707 \pm 0.13$ respectively. The increase in size pointed out effective pegylation of niosomes. The nano size of the pegylated niosomes will probably assist in effective targeting of ABZ to the site of action. The niosomes demonstrated good entrapment efficiency of $98.97 \pm 0.17 \% \mathrm{w} / \mathrm{v}$. As depicted in Figure 2(a) and 2(b), the zeta potential was found to be $-7.86 \mathrm{mV}$ and $3.44 \mathrm{mV}$ for non-pegylated and pegylated $\mathrm{ABZ}$ niosomes respectively. The change in zeta potential again provides evidence of pegylation.

The DSC thermogram [Figure 3(a)] of ABZ displays an endothermic peak at $210^{\circ} \mathrm{C}$ which corresponded to the melting point of drug. This peak of $\mathrm{ABZ}$, however, disappeared in the thermogram of drug loaded pegylated niosomes [Figure 3 (c)] indicating molecular dispersion of $\mathrm{ABZ}$ in the niosomal content.

The XRD analysis [Figure 4(a) and 4(b)] revealed sharp distinct peaks of $\mathrm{ABZ}$ notably at $2 \theta$ diffraction angles of $17.53^{\circ}, 18.73^{\circ}, 19.87^{\circ}, 25.56^{\circ}, 32.67^{\circ}, 38.78^{\circ}$ with $856,1476,905,1763,5429,1179$ respectively. However, a reduction in intensity and number of typical diffraction peaks were observed in the niosomal formulation

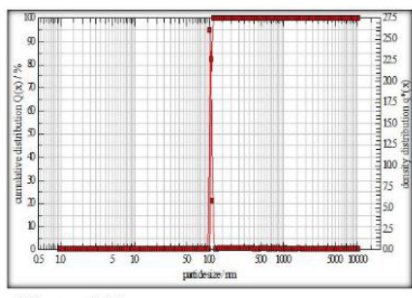

Fig.no.1(a)

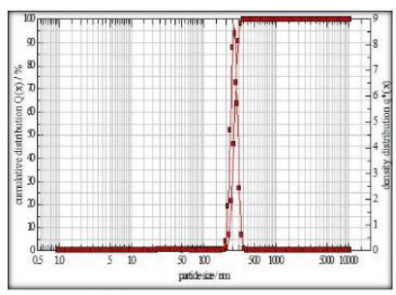

Fig.no.1(b)

Figure 1: Particle size of a) non-pegylated niosomes b) pegylated niosomes.

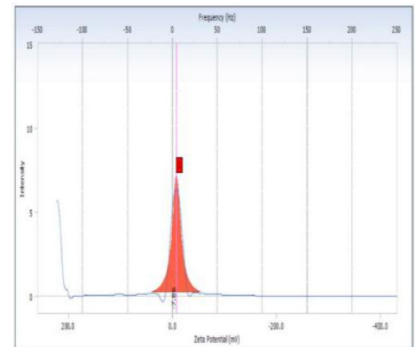

Fig.no.2(a)

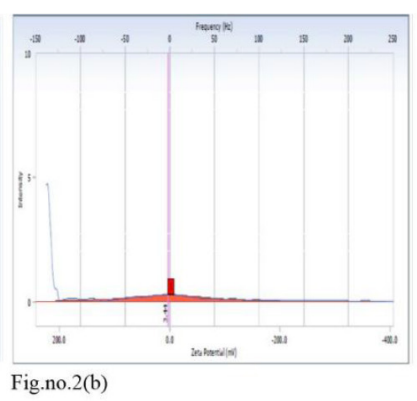

Figure 2: Zeta Potential of a) non-pegylated niosomes b) pegylated niosomes.

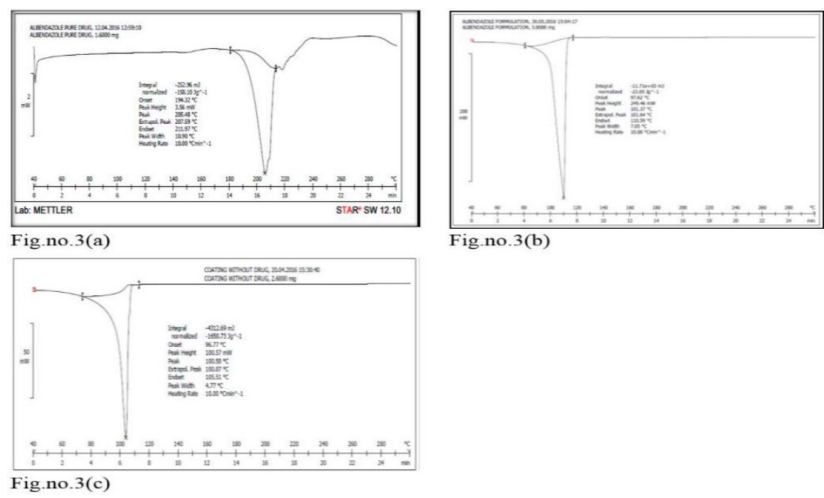

Figure 3: DSC thermogram of a) free $A B Z$ b) pegylated niosomes c) blank pegylated niosomes.
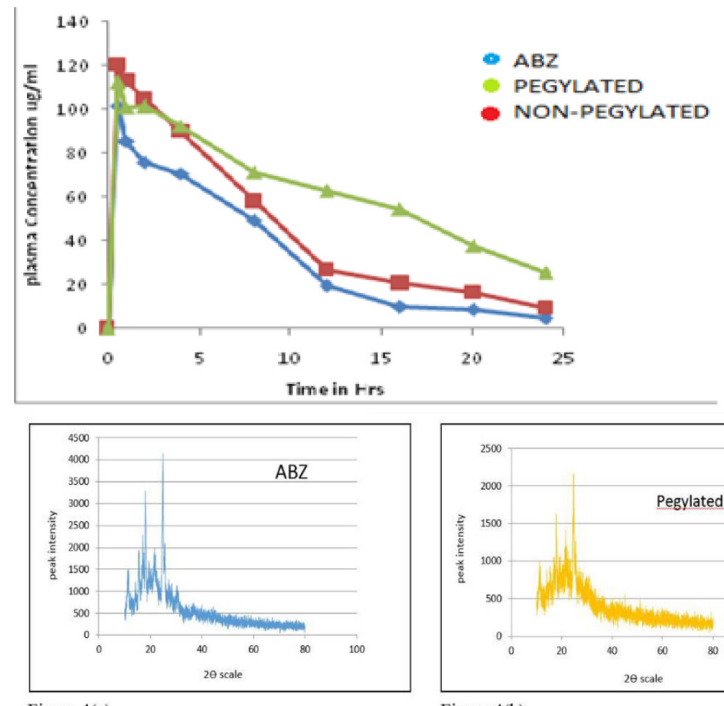

Fig.no.4(a)

Figure 4: XRD image of a) free $A B Z$ b) pegylated niosomes. 


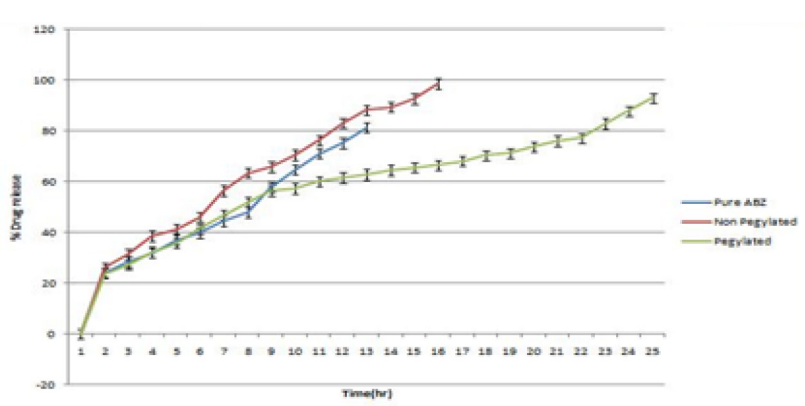

Figure 5: In-vitro release of ABZ from pegylated niosomes, non-pegylated niosomes.

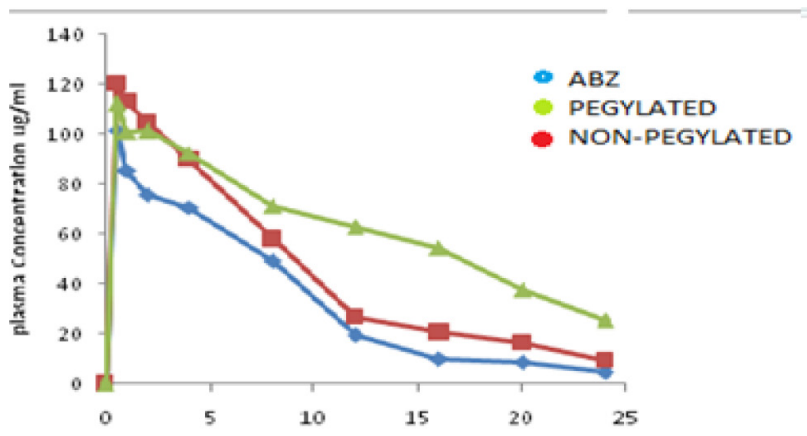

Figure 6: Mean plasma concentration of Albendazole- time curve.

\begin{tabular}{|c|c|c|c|c|c|c|c|c|}
\hline \multirow[t]{2}{*}{ Batch } & \multirow{2}{*}{$\begin{array}{c}\begin{array}{c}\text { Zero } \\
\text { order } \\
\text { model }\end{array} \\
R\end{array}$} & \multirow{2}{*}{$\begin{array}{c}\begin{array}{c}\text { First } \\
\text { order } \\
\text { model }\end{array} \\
\mathrm{R} \\
\end{array}$} & \multirow{2}{*}{$\begin{array}{c}\begin{array}{c}\text { Higuchi/Matrix } \\
\text { model }\end{array} \\
\mathrm{R} \\
\end{array}$} & \multirow{2}{*}{$\begin{array}{c}\begin{array}{c}\text { HixsonCrowell } \\
\text { model }\end{array} \\
r \\
\end{array}$} & \multicolumn{2}{|c|}{$\begin{array}{l}\text { Korsmeyer- } \\
\text { Peppas model }\end{array}$} & \multirow[t]{2}{*}{$\begin{array}{l}\text { Best fit } \\
\text { kinetic } \\
\text { model }\end{array}$} & \multirow{2}{*}{$\begin{array}{l}\text { T90 } \\
\text { Min } \\
\end{array}$} \\
\hline & & & & & $\mathrm{R}$ & $\mathrm{N}$ & & \\
\hline $\mathrm{ABZ}$ & 0.9903 & 0.9552 & 0.9112 & 0.9707 & 0.9761 & 0.91 & $\mathrm{MM}^{*}$ & 720.2 \\
\hline Non-pegylated niosomes & 0.9267 & 0.9382 & 0.9804 & 0.9346 & 0.9708 & 0.42 & MM & 900.4 \\
\hline Pegylated niosomes & 0.7736 & 0.7921 & 0.9882 & 0.7861 & 0.9953 & 0.40 & $\mathrm{KPM}^{*}$ & 1440.8 \\
\hline
\end{tabular}

* MM- Matrix model, KPM- Korsmeyer-Peppas model.

\begin{tabular}{|c|c|c|}
\hline \multicolumn{2}{|c|}{ Table 2: Hemolytic study of niosomes. } \\
\hline Tubes Indication & $\begin{array}{c}\text { Absorbance } \\
\text { (mean } \pm \text { SD) }\end{array}$ & $\% \mathbf{H R}^{*}$ \\
\hline $100 \%$ hemolysis & $0.2879 \pm 0.03$ & - \\
\hline $0 \%$ hemolysis (no hemolysis) & $0.0127 \pm 0.01$ & - \\
\hline $0.25 \mathrm{mg} / \mathrm{ml}$ & $0.0155 \pm 0.02$ & 1.03 \\
\hline $0.5 \mathrm{mg} / \mathrm{ml}$ & $0.0165 \pm 0.01$ & 1.40 \\
\hline $0.75 \mathrm{mg} / \mathrm{ml}$ & $0.0180 \pm 0.07$ & 1.96 \\
\hline $1.0 \mathrm{mg} / \mathrm{ml}$ & $0.0192 \pm 0.04$ & 2.40 \\
\hline $1.5 \mathrm{mg} / \mathrm{ml}$ & $0.0202 \pm 0.09$ & 2.77 \\
\hline
\end{tabular}

*Percent Hemolytic rate, Data was expressed as a mean \pm S.D. where $n=3$

\section{Table 3: Pharmacokinetic parameters of ABZ from} the plasma concentration - time profile in rats.

\begin{tabular}{|c|c|c|c|}
\hline Parameter & Free ABZ & $\begin{array}{c}\text { Non-pegylated } \\
\text { niosomes }\end{array}$ & $\begin{array}{c}\text { Pegylated } \\
\text { niosomes }\end{array}$ \\
\hline Cmax $(\mu \mathrm{g} / \mathrm{ml})$ & 101.6 & 120.25 & 112.05 \\
\hline Tmax $(\mathrm{min})$ & 0.5 & 0.5 & 0.5 \\
\hline $\mathrm{T} 1 / 2(\mathrm{~h})$ & 5.26 & 6.35 & 12.20 \\
\hline $\mathrm{AUC}_{0-\mathrm{t}}(\mu \mathrm{g}-\mathrm{h} / \mathrm{ml})$ & 862.05 & 1196.65 & 1992.14 \\
\hline $\mathrm{MRT}(\mathrm{h})$ & 7.38 & 8.89 & 16.64 \\
\hline $\mathrm{Ke}$ & 0.131 & 0.01 & 0.05 \\
\hline
\end{tabular}

suggesting reduction in crystallinity of ABZ; a property which may help in solubilization of drug.

From Figure 5, it was observed that ABZ in-vitro release was significantly $(\mathrm{P}=0.0278)$ sustained over $24 \mathrm{~h}$ by the pegylated niosomes as $62.85 \pm 2.06 \%$ drug was released from pegylated niosomes in comparison to $81.33 \pm 0.74$
$\%$ of free $A B Z$ in $12 \mathrm{~h}$. As seen in Table $1, \mathrm{~T}_{90}$ i.e time taken for $90 \%$ of drug to be released for $\mathrm{ABZ}$ from pegylated niosomes was remarkably higher (1440 min) than $A B Z$ suspension $(720 \mathrm{~min})$. The kinetics of the drug release was evaluated by model fitting method using PCP Disso v3 software and the model with the highest correlation coefficient amongst them was considered to be the best model. It was found that pegylated niosomes followed Korsmeyer-Peppas order kinetics $(n=0.4089)$, non-pegylated niosomes followed matrix order kinetics $(\mathrm{n}=0.9100)$ and $\mathrm{ABZ}$ follows matrix order kinetics $(\mathrm{n}=0.4268)$. The Korsemeyer - Peppas release model equation is, $\mathrm{F}=(\mathrm{Mt} / \mathrm{M})=\mathrm{km} \mathrm{n}$ Where, $\mathrm{F}=$ fraction of drug release at time t; $\mathrm{Mt}=$ amt of drug release at time t; $\mathrm{M}=$ total amt of drug in dosage form; $\mathrm{K}=$ constant. ' $n$ ' is estimated from linear regression of $\log (\mathrm{Mt} / \mathrm{M})$ Vs $\log$ t. If $\mathrm{n}=0.45$, it indicates Fickian diffusion; $\mathrm{n}<0.45<0.89$ indicates non-Fickian diffusion. Non Fickian diffusion refers to combination of both diffusion and erosion controlled rate release.

Hemolytic study (Table 2) of pegylated ABZ niosomes showed thatpercenthemolytic rateathighestconcentration $(1.5 \mathrm{mg} / \mathrm{ml})$ was found to be less than 3 which indicated that the formulation was compatible with blood.

Pharmacokinetic studies showed that ABZ was detectable in plasma within $30 \mathrm{~min}$ after its administration in rats. As seen in Table 3 and Figure 6, the Cmax of nonpegylated and pegylated niosomes were higher as compared with free ABZ. However, the Cmax of nonpegylated and pegylated niosomes were found to be 
super-imposable. A low value of area under the curve (AUC) was observed with free ABZ. Both the niosomal ABZ displayed high AUC values indicating increased bioavailability of drug. The half-life of ABZ was found to be low $(5.27 \mathrm{~h})$ in comparison with its pegylated (12.20h) and non pegylated forms (6.35h). Sustained release was achieved by niosomal formulations and they exhibited high half-life indicating that drug remains in the body for longer period of time. All these parameters clearly revealed that the prepared niosomal formulation exhibited prolonged release of $\mathrm{ABZ}$ in rats.

\section{CONCLUSION}

The present study concludes that prepared PEGylated niosomes are better options for delivery of ABZ. The results proposed that PEGylated niosomes not only improved the solubility of ABZ but also prolonged the release of drug and the residence time in systemic circulation. This would allow ABZ concentrations in blood for longer period and obviate frequent and larger dosing of ABZ. Moreover, the PEGylated niosomes possess a size sufficient to allow probable entry in to the deep target site in the treatment of echinococcosis, hydatid cysts and neurocysticercosis. Thus, nanosized PEGylated niosomes are promising delivery systems for albendazole and warrant further in vivo experiments.

\section{ACKNWOLEDEGEMENT}

The authors thank P.E Society's Modern College of Pharmacy, Nigdi, Pune for providing the facilities required for carrying out research work.

\section{ABBREVITAIONS}

DSPE: Distearoyl-sn-glycero-3-phosphoethanolamine; PEG: Polyethylene Glycol; nm: nano metre; AE: Alveolar Echinococcosis; ABZ: Albendazole; BCS: Biopharmaceutics Classification System; UV: Ultraviolet; UV vis: ultraviolet visible; $\mathbf{N a C l}$ : sodium chloride; HR: Hemolytic Rate; Cmax: Peak plasma concentration; Tmax: Time to reach peak concentration; $\mathbf{t} 1 / 2$ : Terminal elimination half-life; Ke: Elimination rate constant; AUC: Area Under the plasma Concentrationtime curve; MRT: Mean Residence Time; AUMC: Area Under the first Moment Curve.

\section{CONFLICT OF INTEREST}

The authors declare no conflict of interest.

\section{REFERENCES}

1. Abushhewa MH, Nolan MJ, et al. Genetic classification of Echinococcus granulosus cysts from humans cattle and camels in Libya using mutation scanning-based analysis of mitochondrial. Loci Mol Cell Probes. 2010;24(6):346-51.

2. Gemmell MA. Epidemiology and control of hydatid disease caused by echinococcus granulosus. Int J Parasitology. 1990;20(4):431-56.

3. Kern P, Ammann A, Kron M, et al. Risk factors for alveolar echinococcosis in humans. Emerging infectious diseases. Int J Parasitology. 2004;10(12):2088-93.

4. Davis A, Dixon H, Pawlowski ZS, et al. Multicentre clinical trials of benzimidazole-carbamates in human cystic echinococcosis (phase 2). Bull W Health Organ. 1989;67(5): 503-8.

5. Ashok K, Meena K. Formulation development of an albendazole selfemulsifying drug delivery system (SEDDS) with enhanced systemic exposure. Acta Pharm. 2012;62(4):563-80.

6. Horton RJ. Albendazole in treatment of human cystic echinococcosis: 12 years of experience. Acta Trop. 1997;64(1,2):79-93.

7. Jung $S$, Medina L. et al. Absorption studies of $A B Z$ and some physicochemical properties of the drug and its metabolite ABZ sulphoxide. J Pharm Pharmacol. 1998;50:43-8.

8. Keshmiri $M$, Baharvahdat $\mathrm{H}$, et al. $A B Z$ versus placebo in treatment of echinococcosis. Trans R Soc Trop Med Hyg. 2001;95:190-4.

9. Hemphill A, Mülle J. Alveolar and cystic echinococcosis: towards novel chemotherapeutical treatment options. J Helminth. 2009;83(2):99-111.

10. Tsukada H, Hamazaki K. et al. Potential remedy against Echinococcus multilocularis in wild red foxes using baits with anthelmintic distributed around fox breeding dens in Hokkaido. Japan Laboratory of Parasitology. 60-81

11. Stamatakos M, Sargedi C. Anthelminthic treatment: An adjuvant therapeutic strategy against Echinococcus granulosus. Parasitology Int. 2009;58(2):115-20.

12. Maitiseyiti A, Xiang WW. Efficacy of Albendazole-Chitosan Microspherebased Treatment for Alveolar Echinococcosis in Mice. J Pharm Pharmacol. 1997;53:23-57.

13. Ursula $\mathrm{S}$, Jacques $\mathrm{C}$. Albendazole treatment of echinococcosis in humans: Effects on microsomal metabolism and drug tolerance. Clinical Pharmacol and Therapeutics. 1990;47(3):347-53.

14. Horton R.J. Albendazole in treatment of human cystic echinococcosis: 12 years of experience. Acta Trop. 1997;64(2):79-93.

15. Handjani VR. Dispersion of lamellar phases of nonionic lipids in cosmetic products. Int J Cosmetic Sic. 1979;1(5):303-07.

16. Shakya V, Bansal, BK. Niosomes : a novel trend in drug delivery, Int. J Res Dev Pharm L Sci. 2014;3(4):1036-41.

17. Rokade VS, Kadu PK. Formulation and evaluation of novel antibacterial ciprofloxacin loaded niosomal cream. Int Res J Pharm. 2015;6(8):519-27.

18. Adnan A, Khalid AM. Niosomes in sustained and targeted drug delivery: some recent advances. J Drug Targ. 2009;17(9):671-89.

19. Gannu PK, Pogaku R. Nonionic surfactant vesicular systems for effective drug delivery—an overview. Acta Pharm Sin. 2011;1(4):208-19.

20. Kumar AP, Singh R, et al. Formulation and evaluation of sustained released niosomes containing pregabalin. Int J of Pharm and Life Sci. 2013;4(7):2770-74.

21. Gyati SA, Sharma PK. et al. in vitro and in vivo Evaluation of Niosomal Formulation for Controlled Delivery of Clarithromycin. Scientifica. 2016;1-10. Article ID 6492953.

22. Kalaivani $A$, Chellaram C. Nanoparticle pegylation for imaging and therapy-a review. Ind J Inn Dev. 2012;1(8):2277-5382.

23. Chiraz JM, Roudayna D, Véronique A. et al. Ethanol injection method for hydrophilic and lipophilic drug-loaded liposome preparation. J Lipo Res. 2010;20(3):228-43.

24. Zarei M, Norouzian D. Paclitaxel loaded niosome nanoparticle formulation prepared via reverse phase evaporation method: an in vitro evaluation. Pak J Biol Sci. 2013;16(6):295-98.

25. Rui-xi He, Xi Ye. et al. PEGylated niosomes-mediated drug delivery systems for Paeonol:Preparation, Pharmacokinetics studies and Synergistic antitumor effects with 5-FU. J Lipo Res. 2016;27(2):161-70.

26. Huang $Y$, Chen J. et al. PEGylated synthetic surfactant vesicles (Niosomes): novel carriers for oligonucleotides. J Mat Sci. 2008;19(2):607-12.

27. Azizi S, Norouzian D. et al. Characteristics of pegylated niosomal letrozole. J Chem Pharm Res. 2015;7(2):423-27.

28. Arora V, Rastogi . et al. Pharmaceutical applications of nano-niosomes in drug, vaccine and gene delivery. Int J Pharm Sci Nano. 2014;7(4):2603-11. 
Rogerson A, Cummings J. et al. Niosome as control drug delivery system. J Pharm Pharmacol. 1988;40:337-43.

30. Desai TR, Finely WH. Nebulisation of Niosomal all-trans-retonoic acid:an inexpensive alternative to conventional liposomes. Int $\mathrm{J}$ Pharm. 2000;241(2):311-17.

31. Ruckmani K, Jayakar B, Ghosal SK. et al. Non-ionic Surfactant Vesicles of Cytarabine hcl for Effective Treatment of Leukemias. Drug Dev Ind Pharm. 2000;26(2):217-22.

32. Kandasamy $R$, and Veintramuthu S. Formulation and Optimization of Zidovudine Niosomes. AAPS Pharm Sci Tech. 2010;11(3):1119-27.

\section{PICTORIAL ABSTRACT}

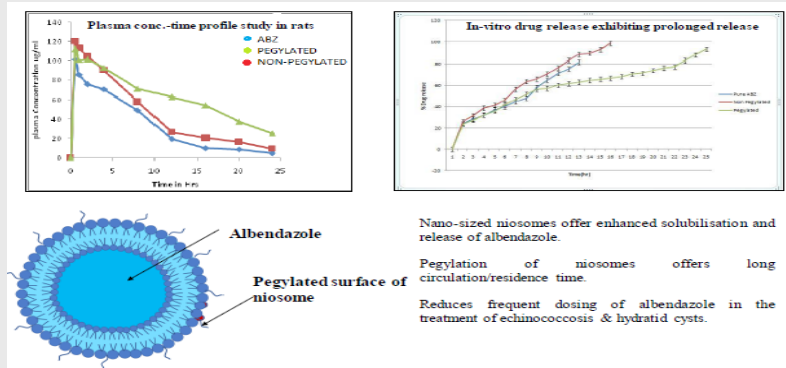

\section{About Authors}

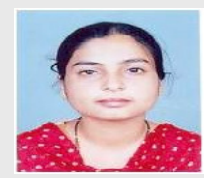

Dr. Mrs. Karimunnisa S. Shaikh: Is currently employed as Professor of Pharmaceutics at P. E Society's Modern College of Pharmacy, Nigdi, Pune. The college is affiliated to Savitribai Phule Pune University, Pune, Maharashtra, India. She pursued Ph.D from Bharati Vidyapeeth University, Maharashtra, India. She was a recipient of National Doctoral Fellowship from AICTE, India. She pursued her B. Pharmacy and M. Pharmacy course from University of Pune, India. She has been contributing to academics since 15 years. She has published articles related to her expertise in several peer reviewed journals of national and international repute. She is a referee for 20 international and national journals. She is actively involved in development of novel drug delivery systems, specifically nanoparticles, liposomes, niosomes, ethosomes and phytopharmaceuticals.

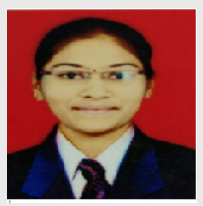

Ms. Puja Pandhe pursued Master degree in Pharmacy from P. E Society's Modern College of Pharmacy, Nigdi, Pune. Currently she is working as QA Officer at Nulife Pharmaceuticals, MIDC, Pimpri, Pune-411018.
33. Bothiraja C, Kapre SH. et al. Development of plumbagin-loaded phospholipid-tween 80 mixed micelles: formulation, optimization, effect on breast cancer cells and human blood/serum compatibility testing. Future Sci. 2013;4(10):1247-59.

34. Ming K, Hyunjin P. et al. Construction of hyaluronic acid niosome as functional transdermal nanocarrier for tumor therapy. Carb Poly. 2013;94(1):634-41.

35. Sayyad R, Wagh S. et al. Anthelmintic activity of aqueous and methanolic extract of Krumina tablet - a polyherbal formulation. Int J Pharm Life Sci. 2014;5(9):976-7126.

36. Hemphill A, Stadelmann B. et al. Treatment of echinococcosis: albendazole and mebendazole - what else. J. Parasite. 2014;21:1-9.

\section{SUMMARY}

- Albendazole demonstrates variable, unpredictable and low therapeutic response $(20 \%$ to $50 \%)$ in the treatment of echinococcosis, hydatid cysts and neurocysticercosis due to its low aqueous solubility. Prescribed dosage is higher doses 2-3 times a day for 6 months to year. There is a need to minimize the dose and dosing frequency which will lead to lesser side effects and thus increase the efficacy of $A B Z$.

- The aim of the present study was to increase the efficacy of $A B Z$ by formulating a long circulating vesicular system. The niosomal encapsulation shall control drug release and PEGylation would further prolong in-vivo release of $A B Z$.

- Thus, pegylated niosomes containing $A B Z$ were prepared and evaluated for size, entrapment efficiency, in vitro drug release, hemolytic activity and in-vivo pharmacokinetic profiling.

- Pegylated ABZ niosomes demonstrated size of $296.39 \mathrm{~nm} \pm 0.62$ with polydispersity index of $0.2707 \pm 0.13$, good entrapment efficiency of $98.97 \pm 0.17 \% \mathrm{w} / \mathrm{v}$ and zeta potential of 3.44 Mv.

- $\mathrm{ABZ}$ in-vitro release was significantly $(\mathrm{P}=$ 0.0278 ) sustained over $24 \mathrm{~h}$ by the pegylated niosomes as $62.85 \pm 2.06 \%$ drug was released from pegylated niosomes in comparison to 81.33 $\pm 0.74 \%$ of free $A B Z$ in $12 \mathrm{~h}$.

- Hemolytic study of pegylated ABZ niosomes showed that percent hemolytic rate at highest concentration $(1.5 \mathrm{mg} / \mathrm{ml})$ was found to be less than 3 which indicated that the formulation was compatible with blood.

- The $C_{m_{a x}}$ AUC and half-life of pegylated niosomes was higher as compared with free ABZ. Sustained release was achieved by pegylated niosomal formulation indicating that drug remains inthe body for longer period of time.

Cite this article: Karimunnisa S, Puja P, Sangita K, Bothiraja C. Development and Evaluation of a Novel Drug Delivery System for Albendazole. Indian J of Pharmaceutical Education and Research. 2018;52(3):408-15. 